\title{
Medievalista
}

Online

$18 \mid 2015$

Número 18

\section{"In oboedientia, sine proprio, et in castitate, sub clausura": a Ordem de Santa Clara em Portugal (sécs. XIII-XIV)}

Tese de Doutoramento em História, especialidade em História Económica e Social Medieval, apresentada à Faculdade de Ciências Sociais e Humanas da Universidade Nova de Lisboa, Julho de 2011. Orientação da Professora Doutora Iria Gonçalves. Disponível em: http://run.unl.pt/ handle/10362/6119.

\section{Maria Filomena Pimentel de Carvalho Andrade}

\section{OpenEdition}

\section{Journals}

\section{Edição electrónica}

URL: http://journals.openedition.org/medievalista/1153

DOI: $10.4000 /$ medievalista. 1153

ISSN: 1646-740X

\section{Editora}

Instituto de Estudos Medievais - FCSH-UNL

\section{Refêrencia eletrónica}

Maria Filomena Pimentel de Carvalho Andrade, «"In oboedientia, sine proprio, et in castitate, sub clausura": a Ordem de Santa Clara em Portugal (sécs. XIII-XIV) », Medievalista [Online], 18| 2015, posto online no dia 01 junho 2015, consultado o 23 setembro 2020. URL : http://journals.openedition.org/ medievalista/1153 ; DOI : https://doi.org/10.4000/medievalista.1153

\section{(c) (7) \&)}

Mediavalista está licenciado com uma Licença Creative Commons - Atribuição-NãoComercial 4.0 Internacional. 
Título: “In oboedientia, sine proprio, et in castitate, sub clausura": a Ordem de Santa Clara em Portugal (sécs. XIII-XIV). Tese de Doutoramento em História, especialidade em História Económica e Social Medieval, apresentada à Faculdade de Ciências Sociais e Humanas da Universidade Nova de Lisboa, Julho de 2011. Orientação da Professsora Doutora Iria Gonçalves. Disponível em: http://run.unl.pt/handle/10362/6119.

Autor(es): Maria Filomena Pimentel de Carvalho Andrade Universidade: Universidade Aberta

Faculdade e Departamento / Unidade de Investigação: Departamento de Ciências Sociais e de Gestão (UAb) / Centro de Estudos de História Religiosa (UCP).

Código Postal: 1269-001

Cidade: Lisboa

País: Portugal

Contacto: fandrade@uab.pt

Fonte: Medievalista [Em linha]. Direc. José Mattoso. Lisboa: IEM.

Disponível em:

http://www2.fcsh.unl.pt/iem/medievalista/MEDIEVALISTA18/andrade1813.html ISSN: 1646-740X

Data do texto: 24 de Maio de 2015 


\title{
Apresentação de Tese I Thesis Presentation
}

\author{
"In oboedientia, sine proprio, et in castitate, sub clausura": a Ordem de Santa Clara \\ em Portugal (sécs. XIII-XIV).
}

Tese de Doutoramento em História, especialidade em História Económica e Social Medieval, apresentada à Faculdade de Ciências Sociais e Humanas da Universidade Nova de Lisboa, Julho de 2011. Orientação da Professora Doutora Iria Gonçalves Disponível em: http://run.unl.pt/handle/10362/6119”.

\section{Maria Filomena Pimentel de Carvalho Andrade}

A dissertação que agora se apresenta tem como objecto uma Ordem religiosa feminina: as Clarissas, que se implantam no território português em meados do século XIII, e a vivência das suas comunidades nas centúrias de Duzentos e Trezentos. O título evidencia a óptica privilegiada, a de uma instituição religiosa com um carisma próprio, que se expressa na fórmula de profissão que as freiras realizam, na presença da abadessa e da sua comunidade: viver "in oboedientia, sine proprio, et in castitate, sub clausura". Trata-se, pois, de compreender o funcionamento de uma entidade, no caso vertente, de cariz religioso, e a vida dos que a constituem num esforço totalizante e relacional.

Comecei por introduzir a temática realizando uma leitura interpretativa do papel da mulher e da sua opção religiosa, num contexto dominado pelo masculino. Esta opção significa contextualizar o monaquismo feminino, como agente e construtor de uma história e o protagonismo dos seus conventos, face aos franciscanos e na conjuntura económica e social portuguesa de então.

No que respeita às fontes, apresentei as que utilizei, evidenciando as discrepâncias na documentação disponível para os diferentes mosteiros. Realizei aindla um estado da 
"In oboedientia, sine proprio, et in castitate, sub clausura": a Ordem de Santa Clara

em Portugal (sécs. XIII-XIV). - Maria Filomena Pimentel de Carvalho Andrade

questão relativamente ao estudos já efectuados sobre esta temática, colocando em evidência como, apesar da florescente investigação, em outros países, sobre as clarissas e o fenómeno mendicante despoletado pelo exemplo do Poverello de Assis, entre nós pouco se fez após a profícua investigação de ilustres investigadores, todos eles franciscanos, como Félix Lopes, Pinto Rema ou António Montes Moreira. Procedi depois a um breve esclarecimento sobre a utilização de alguns conceitos e ainda as balizas cronológicas usadas, desde meados do século XIII, com a canonização de Clara (1255) e a implantação da primeira comunidade de clarissas em Portugal (1258) ao final do século XIV, marcado pelo início de uma nova era de reformas e novas observâncias, no que aos Mendicantes respeita.

O meu estudo foi sempre norteado pelo intento de compreender uma Ordem feminina cuja fundadora, uma mulher dotada de um carisma muito próprio, soube agregar em torno da sua experiência religiosa um conjunto de outras mulheres. Para elas comporia e conseguiria ver aprovada, em tempos adversos a inovações normativas, uma Regra própria, conseguindo inclusivé do Papado a licença para viver numa rigorosa pobreza. Apesar das mitigações infligidas posteriormente a este corpus normativo, em larga medida por pressão dos próprios pontífices, no quadro das amplas discussões, no seio dos mendicantes, em torno da vivência da pobreza, a experiência de Clara e das Damianitas daria origem a um movimento religioso que rapidamente se espalharia por toda a Europa de então.

Organizei a análise a que me propus em torno de três problemáticas ou questionamentos. A primeira linha condutora respeita ao estudo da institucionalização da Ordem em Portugal (com 4 conventos no século XIII - Santarém, Entre-os-Rios, Coimbra e Lisboa - e 5 conventos no XIV - Vila do Conde, Guarda, Beja, Portalegre e Amarante). Nesta análise, procurei apresentar os processos de fundação dos mosteiros em presença, tendo em conta vários aspectos considerados estruturantes: as etapas de fundação (inceptio - conjunto de doações; a receptio e a promotio - aceitação por parte da Ordem da nova casa; assignatio - reconhecimento oficial; autorização papal e do Ordinário do Lugar); o papel dos fundadores nestes processos; as condições de vivência nos espaços interiores e exteriores (a escolha dos locais de implantação e as condições de construção; a vivência do espaço) e, por último, a normativa/regra de vida em comunidade.

Medievalista online № 18| Julho - Dezembro 2015 ๑ IEM - Instituto de Estudos Medievais 3 www2.fcsh.unl.pt/iem/medievalista 
"In oboedientia, sine proprio, et in castitate, sub clausura": a Ordem de Santa Clara

em Portugal (sécs. XIII-XIV). - Maria Filomena Pimentel de Carvalho Andrade

As conclusões a que cheguei apontam para diversos aspectos importantes. Assim, estes mosteiros femininos, no que se conhece, são maioritáriamente de fundação feminina e alguns têm mesmo na sua origem grupos de beatas ou mulheres que vivem a sua opção religiosa fora dos cânones das instituições “dominantes”. Nos primeiros cenóbios, é claro o papel de um programa fortemente apoiado pelo papado, mas já no século XIV, esta influência dilui-se, embora permaneça a necessária autorização pontifícia (e o papado não se coibe, como é natural, de dirimir as questões que chegam até ele), e a iniciativa cabe aos nobres e/ou endinheirados de então.

Todos os processos enfrentam dificuldades de vária ordem, sobressaindo o caso de Coimbra, pela demora e pela forma como este foi resolvido. Mas em todos os outros, a oposição dos bispos, ou de membros do clero local, dificultou a instalação dos conventos. Já para não falar das dificuldades materiais (decorrentes da faltas de dinheiro para conclusão das obras - Entre-os-Rios e Santarém, ou de guerras, acidentes e catástrofes naturais - Guarda, Beja) e ainda dos problemas com famílias nobres que cobiçam e litigam com os cenóbios pela posse dos seus bens (Entre-os-Rios).

A relação com os franciscanos é quase sempre positiva, embora permaneça muito velada. No que à cura de almas respeita, parece não ter sido esta exclusiva dos mendicantes, embora estes aparecem muito claramente em Coimbra e Lisboa (nos processos de fundação e apoio à edificação). Resta saber como se processava realmente esta relação institucional, para lá do que a Regra determinava ou do que ficou nos documentos das Clarissas. Parece certo que a proximidade (nem sempre requerida) leva a um interesse e intervenção destes nos mosteiros das suas irmãs. Valerá a pena questionar, de forma mais explícita, a dependência das fundações femininas face a uma prévia ou concomitante fundação masculina.

Na vida interna, a forma como a Regra é vivida e o facto de termos para um dos Mosteiros umas “Constituições”, levam-nos a afirmar que o $4^{\circ}$ voto, o de clausura (a novidade da época) era cumprido, até porque a existência de “irmãs de fora” o permite no que às freiras diz respeito. Mas encontramos também muita "gente" a entrar no mosteiro e, pelo que se conhece de Santa Clara de Coimbra, a presença de senhoras nobres (como a Rainha Santa Isabel) seria possível, bem como de crianças de ambos os

Medievalista online № 18| Julho - Dezembro 2015 ๑ IEM - Instituto de Estudos Medievais 4 www2.fcsh.unl.pt/iem/medievalista 
"In oboedientia, sine proprio, et in castitate, sub clausura": a Ordem de Santa Clara

em Portugal (sécs. XIII-XIV). - Maria Filomena Pimentel de Carvalho Andrade

sexos - filhos/as ou sobrinhos/as das freiras que aí eram criados/as - ou ainda de alguns dos seus dependentes e servidores.

Uma segunda linha de análise desenvolve-se em torno das questões que se prendem com o estabelecimento e compreensão das formas como estas comunidades conseguem sobreviver e economicamente subsistir, apesar das dificuldades que ameaçam estas mulheres. Apenas em três dos mosteiros (Santarém, Entre-os-Rios e Coimbra) foi possível fazer esta análise, uma vez que os restantes não possuem documentação patrimonial. Depois de apresentar a formação do património, individualizando a dotação inicial, observa-se as várias formas commumente utilizadas para constituir o património, assim como a organização e gestão do mesmo.

Em todos estes mosteiros, é visível a importância do papel da dotação inicial, embora nalguns casos e devido a várias viscissitudes, ela se torne escassa, numa economia em permanente evolução e com várias crises que afectam em especial o sector agrícola.

No entanto, cada um dos três mosteiros analisados, é um caso, porque a situação patrimonial está directamente ligada à região em que o cenóbio se implanta e ao recrutamento que faz.

Assim, Santarém é um mosteiro com um patromónio circunscrito às regiões mais ricas do Portugal medieval, Santarém e Lisboa e às suas envolventes. Por isso, introduzido na economia de mercado, cedo começa a usar a moeda e a exigi-la no pagamento das suas rendas e dos seus encargos.

Entre-Ambos-os-Rios é um típico mosteiro de pequenas dimensões, ligado a uma família patronal do Entre-Douro-e-Tâmega (onde dominam os interesses da velha nobreza portuguesa e até leonoesa), sujeito à cobiça dos senhores das terras que o rodeiam. Vive com base na economia de terras ricas e rentáveis - um couto, e outras leiras repartidas pela paisagem -, servindo um burgo (que criou à sua volta) e dele se servindo para cultivar as terras e para vender os produtos, embora o Rio Douro acabe por transformar esta micro-economia numa economia com apetências para o mercado. É esta conjuntura que levará, no século $\mathrm{XV}$, à transferência deste cenóbio para o Porto, conservando estes mesmos bens.

Medievalista online № 18| Julho - Dezembro 2015 ๑ IEM - Instituto de Estudos Medievais 5 www2.fcsh.unl.pt/iem/medievalista 
"In oboedientia, sine proprio, et in castitate, sub clausura": a Ordem de Santa Clara

em Portugal (sécs. XIII-XIV). - Maria Filomena Pimentel de Carvalho Andrade

Em Coimbra, estamos perante um Mosteiro real com uma propriedade que se estende a quase todo o reino (com excepção do Sul) e com uma gestão própria de um grande e poderoso senhorio.

Mas estes mosteiros são comunidades vivas e actuantes e, por isso, num terceiro momento e face às questões levantadas, debrucei-me, então, sobre as comunidades humanas, as suas figuras tutelares - patronos/fundadores, benfeitores (reis, bispos e nobres) e protectores -, e a sua organização (vida conventual), tendo em conta o recrutamento das freiras e as redes familiares e clientelares que estabelecem - com a família biológica e com a nova família conventual (dependentes, servidores, foreiros). Deste estudo, pude concluir que é fundamental sublinhar o papel de todas estas figuras tutelares, desde os fundadores/patronos aos que se intitulam governadores e aos benfeitores, onde identificamos um enxame de gente titular e de clérigos, participantes, não apenas dos trabalhos do mosteiro mas, acima de tudo, agraciados com a protecção da família conventual, participando dos seus dons e das suas graças. Nos primeiros tempos, encontramos senhores (mulheres e homens da nobreza e mesmo da realeza) a apoiar as fundações, mas bem depressa a pequena nobreza e a burguesia em ascenção (mercadores e funcionários) se interessam pelo movimento mendicante e pelas damianitas.

Não é alheia a esta realidade o recrutamento das monjas que se faz no seio destas famílias que, por vezes, têm simultaneamente no mosteiro, mães e filhas, tias e sobrinhas. E entre elas, no interior do cenóbio, tende a perpetuar-se o parentesco sanguíneo, criando outros laços de carácter espiritual, mas que têm importantes consequências a nível da orgânica interna da comunidade: na ocupação de cargos e serviços e nas questões e alianças que surgem e se desenvolvem, a nível espiritual e mesmo material.

Formada a nova família conventual, a ela se juntam os dependentes, servidores e trabalhadores que participam na vida conventual, pois sem eles não seria possível sobreviver. Torna-se o cenóbio (comunidade de irmãs) num centro congregador de actividades, centro de vida não apenas espiritual mas também económica e social. 
"In oboedientia, sine proprio, et in castitate, sub clausura": a Ordem de Santa Clara

em Portugal (sécs. XIII-XIV). - Maria Filomena Pimentel de Carvalho Andrade

A institucionalização destas casas monásticas, com toda a sua relação com a sociedade de então permitiu-lhes, assim, uma verdadeira e plena integração no mundo, permanecendo em clausura.

Como complemento necessário e ilustrativo deste trabalho realizei vários anexos (listagens de frades franciscanos, dependentes, serviçais e foreiros, bem como os membros da casa da Rainha D. Isabel e ainda as árvores genealógicas) que estão aqui ao serviço de uma melhor compreensão do texto e não como simples apêndices, constituindo eles mesmo prova do muito que afirmo. Destes realço o conjunto das pequenas biografias (177, no total) que, além dos dados fornecidos pela documentação das clarissas, recolhem ainda os contributos de outras teses que igualmente realizaram prosopografias de monjas e freiras.

Mas, num trabalho desta índole e com esta abrangência, muitas são as questões que ficam em aberto. Entre estas, não quero deixar de realçar duas que, em meu entender, necessitam de um urgente tratamento e para as quais creio que o meu trabalho abre algumas pistas mas, acima de tudo, interroga e “exige” respostas:

- O estudo da Ordem dos Franciscanos - a sua implantação conventual e os movimentos de reforma que perpassam e se afirmam ao longo do seu crescimento, durante a Idade Média e o primeiro século da modernidade.

- As formas de vida religiosa femininas, não apenas as enclausuradas, mas ainda as que escolheram uma forma de vida "mais marginal”, porque (ainda não) institucionalizada, das emparedadas aos grupos de mulheres religiosas sem qualquer regra aprovada.

O ensaio aqui apresentado só foi possível graças ao trabalho já desenvolvido por muitos historiadores que me precederam, e com o contributo de muitos dos meus colegas de ofício, em especial os que comigo se cruzaram nos corredores e se detiveram nas salas de leitura de tantas bibliotecas e arquivos, num labor de pesquisa e de diálogo que tornam possível e enriquecem a construção histórica.

\section{COMO CITAR ESTE ARTIGO}

Referência electrónica:

Medievalista online № 18| Julho - Dezembro 2015 ๑ IEM - Instituto de Estudos Medievais 7 www2.fcsh.unl.pt/iem/medievalista 
"In oboedientia, sine proprio, et in castitate, sub clausura": a Ordem de Santa Clara

em Portugal (sécs. XIII-XIV). - Maria Filomena Pimentel de Carvalho Andrade

ANDRADE, Maria Filomena Pimentel de Carvalho - "Apresentação de Tese/ Thesis Presentation: "In oboedientia, sine proprio, et in castitate, sub clausura": a Ordem de Santa Clara em Portugal (sécs. XIII-XIV). Tese de Doutoramento em História, especialidade em História Económica e Social Medieval, apresentada à Faculdade de Ciências Sociais e Humanas da Universidade Nova de Lisboa, Julho de 2011. Orientação da Professora Doutora Iria Gonçalves. Disponível em: http://run.unl.pt/handle/10362/6119”.

Medievalista [Em linha]. No 18 (Julho - Dezembro 2015). [Consultado dd.mm.aaaa].

Disponível em

http://www2.fcsh.unl.pt/iem/medievalista/MEDIEVALISTA18/andrade1813.html ISSN 1646-740X.

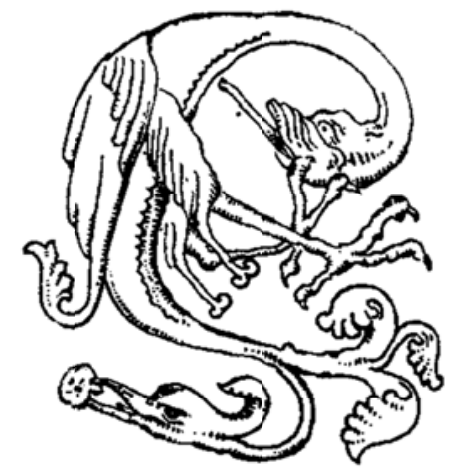

